\title{
Pesquisa-ação em educação: reconhecendo o sujeito contextualizado e os problemas educacionais ${ }^{1}$
}

\author{
XIANG Beili \\ Beijing Normal University
}

\section{Resumo}

A pesquisa-ação considera o sujeito como "o ator da contextualização" (Xia, 2006). Durante o processo da pesquisa, com membros de um grupo de leitura e estudo da pós-graduação na Beijing Normal University, realizei entrevistas, análise documental e bibliográfica e amadureci, gradativamente, de uma pesquisadora descontextualizada para uma pesquisadora-atora, capaz de visualizar a contextualização, além de interpretar, paulatinamente, o sujeito e os problemas educacionais como partes de uma interação recíproca do indivíduo com o seu contexto histórico, político, econômico, cultural e socialmente institucionalizado. No tratamento de objetividade, a pesquisa-ação em educação consiste em reestruturação da filosofia da pesquisa.

Palavras-chave: Pesquisa-ação. Sujeito. Contextualização. Leitura. 


\section{Action research in education: recognizing the contexualized subject and problems}

Action research considers the subject as "the actor of contextualization" (Xia, 2006). During the research process, with members of a postgraduate reading and study group, at Beijing Normal University, I conducted interviews, document and biblioghaphic analysis, and I gradually matured, from a researcher out of context to a researcheractor, capable of vizualizing contextualization, in addition to interpreting, gradually, the subject and educational problems, as parts in a reciprocal interacion of the individual with his historical, political, economic, cultural, and socially institutionalized context. Objectivelly, action research in education consists of restructuring the philosophy of research.

Keywords: Action Research. Subject. Contextualizing. Reading.

\section{Investigación-acción en educación: reconociendo el sujeto contextualizado y los problemas educacionales}

La investigación-acción considera al sujeto como "el actor de la contextualización" (Xia, 2006). Durante el proceso de la investigación, con miembros de un grupo de lectura del posgrado en la Beijing Normal University, fueron realizadas entrevistas, análisis documental y bibliográfica y pasé a ser, gradualmente, de una investigadora descontextualizada a una investigadora actora, capaz de visualizar la contextualización, además de interpretar, paulatinamente, el sujeto y los problemas educacionales como partes de una interacción recíproca del individuo con su contexto histórico, político, económico, cultural y socialmente institucionalizado. En el tratamiento de objetividad, la investigación acción en la educación consiste en la reestructuración de la filosofía de la investigación.

Palabras-clave: Investigación-acción. Sujeto. Contextualización. Lectura. 


\section{Introdução: visualizando a criança contextualizada - “Meu Pé de Laranja Lima" como referência da sociologia histórica}

Minha exploração primeira sobre a contextualização da criança originou-se do livro Meu Pé de Laranja Lima. Na minha visão, a ficção autobiográfica Meu Pé de Laranja Lima, do autor brasileiro, José Mauro de Vasconcelos (1920-1984), pode ser considerada como uma história oral da família de classe baixa e miscigenada do Brasil na década de 1920, narrada pela literatura infantil (Vasconcelos, 2010). Em uma América Latina, onde os contadores da própria história provenientes do campo e da classe baixa urbana eram inexistentes, Meu Pé de Laranja Lima não só carrega um valor literário importante, mas também exerce um peso valoroso nos estudos históricos e sociológicos.

0 nome do protagonista da ficção, “Zezé”, é um apelido carinhoso de José; este, por sua vez, de linhagem metade indígena e metade português, nasceu em 26 de fevereiro de 1920, em uma família pobre da cidade de Bangu, Rio de Janeiro, Brasil. Ele foi treinador de peso-pena, carregador de banana, pescador, modelo, professor do ensino fundamental, do Centro dos Pescadores, entre outras profissões. Após notar que possuía talento para contar histórias, iniciou sua carreira de escritor. Sua obra pioneira, Banana Brava, foi lançada em 1942, quando ele tinha 22 anos. Nos seus 64 anos de vida, 21 obras foram publicadas.

\section{0 “Zezé” da contextualização}

\section{Os dedos magros da pobreza}

Rio de Janeiro, Brasil, 1925 Baía de Guanabara

As crianças vestidas de roupas coloridas e seus familiares desfrutavam confortavelmente a paisagem aérea do Rio de Janeiro, rodeado de belas montanhas, águas e de um bonde no morro Pão de Açúcar, que iniciara sua operação em 1908. Zezé, de cinco anos de idade, junto com seu irmão, Luís, de dois anos, brincavam com uma linha de barbante, na qual colocavam cem botões, amarrando uma extremidade na grade e a outra no dedinho de Luís. Zezé empurrava os botões de uma extremidade a outra, fazendo-os escorregarem um atrás do outro. Eis seu bonde de Pão de Açúcar: em cada vagão lotavam os seus conhecidos.

Em casa, não pagavam aluguel havia oito meses. 0 pai de Zezé estava desempregado há meio ano, e a mãe e a irmã mais velha tinham ido trabalhar numa fábrica de fiação. Zezé era o sexto filho da casa. Uma irmã mais velha fora 
doada ainda na infância. Um par de irmãozinhos morrera pequeno. Após Luís - a quem Zezé atribuiu o apelido de "rei”, nona criança da casa - nasceram mais dois filhos. Naquele ano, as crianças não receberam nenhum presente de $\mathrm{Natal} . \mathrm{Na}$ noite natalina, embaixo da luz ofuscante da lamparina de óleo, pois a empresa da luz cortara a energia, a pobre família mastigava a tristeza como ceia de natal em silêncio.

\section{0 contexto da rápida industrialização, classe social, raça e gênero de Zezé}

0 retrato transversal e sensibilizado da família nos anos 1925 e 1926, projetado por José, espelhou a opressão que a família de Zezé sofreu da industrialização, classe social, raça e gênero social ${ }^{2}$. 0 desemprego do pai refletiu a grave ameaça de desemprego que os operários latino-americanos sofriam na década 20 do século XX. Em 1920, 69,7\% da mão de obra brasileira ocupavam a produção agrária, e $16,5 \%$ trabalhavam no setor terciário. 0 pai de Zezé pertencia ao grupo de $13,8 \%$ proletariados que representavam a produção industrial. Naquela época, mesmo nos tempos mais prósperos, com pouca turbulência econômica, a ameaça do desemprego na América Latina continuava problemática. Qualquer pequena resistência por parte dos operários à fábrica podia desencadear vinganças sérias (Bethel, 1992). 0 pai de Zezé foi despedido justamente por ter brigado com um dos administradores da fábrica. A mãe e a irmã mais velha se sentiram obrigadas a trabalhar na fábrica. Naqueles tempos, as mulheres brasileiras foram maciçamente empregadas; no entanto, seus salários eram substancialmente mais baixos do que os dos homens (cf. Burns, 1989).

A dificuldade de sustentar a família vivenciada pelos pais de Zezé estava relacionada ainda com a questão racial da família miscigenada. 0 pai de Zezé era português; a mãe, indígena. No final do século XIX, o Brasil entrou em uma era preconceituosa contra os mestiços. Os europeus eram considerados os mais elevados pelo psicólogo social Gustave Le Bon; já aqueles nascidos descendentes da mistura de raças eram inferiores até mesmo que os próprios pais. Manuel Bonfim e outros intelectuais brasileiros também criticavam e acusavam a raça

2. Em meados da década de 20 do século $X X$, a América Latina ingressou em um processo de rápida industrialização. O trem "Mangaratiba", que atravessava agressiva e arrogantemente a cidade e que no final roubou a vida do seu Portugal, era símbolo de uma industrialização acelerada. Conforme consta em História da América Latina de Cambridge, para a fluidez assídua das mercadorias trazidas do interior, em 1930, o Brasil já havia construído 32 mil quilômetros de ferrovias. (Bethel, 1992) 
mestiça pelo atraso e bagunça da América Latina (Burns, 1989, p. 262). Não foi à toa que a irmã mais velha, Glória, ao levar Zezé para realizar a matrícula na escola, omitiu seu nome do meio "Pinagé”, que denunciava o segredo racial da mãe. Zezé ficou incrustado nesse espaço tridimensional traçado pela longitude e latitude da estrutura social, histórica, política, econômica e culturalmente construída.

A influência interativa de Zezé com este espaço tridimensional e seus demais elementos constituiu a "contextualização" de Zezé, determinando concretamente "esta" criança: este garoto chamado "Zezé”, que vivia em uma família mestiça de classe social baixa - como muitos filhos do Brasil da década de 1920 -, existência esta de uma interação mútua entre o sujeito de corpo e alma com a sua estrutura social e histórica. Entretanto, no âmbito educacional e da crítica da literatura infantil, a contextualização da criança muitas vezes é encoberta.

\section{A visão hipotética da criança: o (des)cobrir da "criança"}

A visão hipotética da criança é uma resposta à pergunta "Que tipo de ser a criança é?". Pode-se indubitavelmente discutir o bondinho de Pão de Açúcar feito de barbante e botões por meio da perspectiva de inocência, espírito lúdico, imaginação e infantilidade de Zezé, além de poder entendê-lo, brincadeira inventada por Zezé, inserindo-o no contexto histórico social de uma família brasileira de classe baixa na década de 1920 do século XX: a família não possui recurso econômico suficiente para que as crianças pudessem experimentar o verdadeiro bonde. Caso Zezé não fosse brasileiro, tampouco vivesse na década de 1920 e se sua família pertencesse à classe média ou fosse monoétnica, a brincadeira inventada apresentaria outros aspectos. Dessa forma, o lúdico é carregado de marca da contextualização sóciohistórica.

A ficção que descreveu friamente a tristeza e o desespero de Zéze de cinco anos de idade, acrescida da repreensão dos pais e da irmã mais velha, motivou meu apelo sobre o tema: "a ternura necessita de uma básica segurança econômica" (Xiang, 2010). Zhou Xiaopo discutiu a questão de como a violência rígida da família fez com que o espírito de Zezé fosse dotado de ódio. No entanto, a grande dor de Zezé foi dissolvida, no fim, pelo tenro amor e atenção da mesma família (Zhou, 2010). Na verdade, a relação pai-filho também é resultado da interação da estrutura social com o indivíduo: os pais que brigavam e espancavam Zezé são os mesmos que desejavam the dar amor tenro. Entretanto, quando os dedos magros da pobreza ameaçam a segurança econômica da família, isto é, quando a sustentação das necessidades básicas da vida requer esforços enormes e os trabalhos cotidianos praticamente esgotam a força física e espiritual dos pais, a ternura é espremida, 
escondida, não transmitida.

0 tempo se estendeu, passaram-se 70 anos. Mediante a pesquisa antropológica a partir da "metodologia de abordagem naturalista", a socióloga e professora da Universidade Temple, Annette Lareau, revelou que a estrutura social e a interação entre pais e filhos nas famílias pobres dos Estados Unidos na década de 1990 eram semelhantes às da casa de Zezé. Durante os anos de 1990 a 1994 , Lareau e sua equipe de pesquisa realizaram observações e entrevistas com 12 famílias de estudantes do quarto ano escolar, de 9-10 anos, as quais eram da classe média, dos proletariados e dos pobres (seis famílias brancas, cinco famílias negras e uma família mestiça). Assim como Zezé apanhava de cinto do pai, na pesquisa investigativa de Lareau, um garoto branco do quarto ano escolar, Billy, oriundo de uma família pobre, também sofreu chicotadas de cinto da própria mãe. A equipe de pesquisa descobriu que existem diferenças importantes dentro da uma mesma classe social: nem toda relação pai-filho da família da classe do proletariado apresenta espancamento e briga; assim nos ambientes cujas condições econômicas são iguais ou semelhantes, as reações de cada unidadefamília podem ser distintas. Não obstante, o comportamento de açoitar a criança com cinto não foi observado nas famílias de classe média. (Laureau, 2010, p. 228s)

Apesar de existirem diferenças na mesma classe social, a equipe de pesquisa de Lareau constatou de forma sutil que existe uma unanimidade no que diz respeito à desigualdade dos recursos nas diferentes classes sociais: os pais proletários e pobres gastam mais tempo, mostram-se mais cansados e frustrados na quesito sustento da família e cuidados com as necessidades básicas dos filhos do que os pais da classe média. Por falta de recursos a longo prazo, problemas mínimos podem desencadear sérias e profundas consequências. Embora outras famílias de status financeiro diferente também sofram igualmente das questões que as famílias pobres apresentam, por exemplo, abuso sexual, depressão crônica e infecção de AIDS, a desigualdade dos recursos das famílias de diferentes classes é extremamente problemática.

0 crescimento da criança passa pelo filtro de sua interação com a estrutura sócio-histórica. Portanto, em relação à visão hipotética da criança, minha resposta é: a "criança" é o sujeito da contextualização histórica e social. Ao nascer, ela já se constitui como um campo de influência recíproca do sujeito com a ideologia social, de classe, racial (etnia), de gênero e sexual. Assim, eu concordo com a hipótese do professor Ma Li (2005) de que "a criança é um ser": desde o nascimento, a criança é um ser racial, social, cultural, e não um indivíduo completamente natural. Antigamente, aquilo que os teóricos cunharam de "puerilidade" ou o espírito verdadeiro, bondoso e belo da criança nunca existiu, pois é apenas um ideal artístico e conceito estético do mundo dos adultos. Se nós não reconhecermos que Zezé é 
um "indivíduo" concreto - um sujeito contextualizado histórico e socialmente -, as análises provavelmente serão superficiais e estreitas.

A literatura é uma área que descreve objetiva e vigorosamente as condições e o estado de uma pessoa. Na minha visão, se o educador cultivar as qualidades literárias, poderá melhor compreender o “sujeito”, entender a criança. Nesse sentido, é mais provável que o educador desenvolva estratégias educacionais e pedagógicas adequadas, as quais incentivam o crescimento da criança. Na verdade, a disciplina de "literatura infantil" foi um dos componentes mais importantes do currículo pedagógico do curso de pedagogia da Herzen State Pedagogical University of Russia da ex-URSS (Wu, 2009). Além disso, tanto a Beijing Normal University quanto o Instituto de Línguas da Zhejiang Normal University estabeleceram o curso de literatura infantil na formação dos docentes. (Wang, 2006)

\section{Visualizando o aluno na contextualização: análises de dados educacionais}

No III Congresso do Estreito China-Taiwan sobre Pesquisa-Ação, convocado por Taiwan, nos dias 1 a 8 de outubro de 2010, o artigo-resposta submetido pela professora Chen Huimin da Beichang Escola Nacional de Ensino Fundamental, município de Hualian em Taiwan, demonstrou profundamente o seu "visualizar" do sujeito e os problemas educacionais incrustados na estrutura social.

\section{0 estudante no contexto da realização do trabalho de pesquisa}

A professora Chen Huimin já desenvolveu estudos sobre estudantes nos anos escolares elementares e avançados do ensino fundamental. Antes, deparava-se com o problema de o aluno não conseguir entregar o trabalho de pesquisa no prazo estipulado. Investigou, então, os recursos culturais das famílias dos alunos: aqueles que possuíam computador em casa, com condições de acessar a internet, não excediam 1/3; igualmente, eram poucas as famílias que contavam com acervos de enciclopédia para que os filhos pudessem realizar pesquisas; por fim, mais raro ainda eram os pais que levavam os filhos à biblioteca para fazerem pesquisas ou pegarem livros emprestados. A professora Chen percebeu que, para a maioria dos estudantes, requisitar trabalhos de pesquisa e busca por informações fora da sala de aula não era uma tarefa fácil. (Wang, 2006)

Somente esclarecendo a estrutura social, na qual a criança de diferentes origens familiares está inserida, e os recursos culturais que desfruta, é que conseguiremos desenvolver estratégias pedagógicas apropriadas. Em relação àquelas famílias de 
“condições culturais mais deficitárias", a professora Chen distribuiu diferentes trabalhos, mais adequados, para que todos os alunos provenientes de classes sociais distintas pudessem realizá-los; além de proporcionar recursos suficientes para o uso e a aplicação dentro da escola. Por exemplo, nas pesquisas sobre contos infantis e invenção - entre Oscar Wilde ${ }^{3}$ e Nankichi Niimi ${ }^{4}$-, ela escolhia o primeiro, pois "a amplitude daquele é abrangente, a quantidade e os tipos de informação possíveis para a realização do trabalho também são mais abundantes, facilitando, consequentemente, aos alunos obter os dados necessários" (Wang, 2006). Mais do que isso, ela disponibilizava dados na sala de aula para fins de consulta dos alunos, auxiliando aqueles que apresentavam condições culturais mais baixas a concluírem o trabalho.

\section{A contextualização da cooperação família-escola}

No campo da cooperação família-escola, a professora Chen analisou que os eventos de interação família-escola, organizados pela escola, comumente são baseados no padrão de vida dos professores, apresentando, assim, as características de classe média e alta. Os pais que participam são muitas vezes aqueles que apresentam condições próximas das do professor, isto é, da classe média e alta. Já muitos pais de origem social mais baixa são excluídos imperceptivelmente da porta da escola. Chen formulou razões que podem explicar a baixa motivação das famílias de classe popular nos eventos escolares: é possível que os pais não gozaram de boas experiências escolares. Consequentemente, a vontade de participar das atividades interativas família-escola é reduzida. Ou, ainda, por não apresentarem escolaridade suficiente, sentem dificuldades em atender à expectativa do professor de responsabilizá-los pelos estudos dos filhos. Para diminuir as pressões, preferiam não participar das interações família-escola.

Dessa forma, a professora Chen, a partir da análise das classes sociais, propôs estratégias de gestão da cooperação família-escola: é recomendável ao professor, na sua interação com os pais, auxiliar aqueles da classe social baixa a educarem seus filhos, ou orientá-los a como ajudar nas tarefas escolares destes. Já para um gestor escolar é necessário buscar formas e meios alternativos adequados a todos os pais de classes sociais distintas para a participação na educação escolar.

A pesquisa-ação da professora Chen Huimin é baseada nos diferentes alunos

3. Oscar Wilde (1854-1900): dramaturgo, poeta e ensaísta inglês.

4. Nankichi Niimi (1913-1943): escritor japonês da literatura infantil. 
e suas famílias, incrustados em estruturas e meios sociais distintos, bem como no "visualizar" da existência de um contexto de relações sociais e mecanismos de funcionamento deste meio. Ao refletir sobre as próprias ações, tornou-se uma motivadora de transformações, como demonstrado pelo professor Xia (2006) quando afirma "o trabalho elementar de uma metodologia coletiva com orientação para a reforma social".

\section{Visualizando a contextualização do sujeito e a sociedade da "leitura": minha pesquisa-ação com a orientanda Yan}

Desde setembro de 2009, eu e a minha mestranda Yan identificamos na nossa interação de intersubjetividade a contextualização do sujeito e a sociedade da "leitura”. Nessa caminhada, eu reconsiderei se a leitura deve ser ou não um prérequisito da aprovação dos estudantes na pós-graduação. 0 meu entendimento acerca da leitura e o dela, e a organização do grupo de leitura, mudaram nesse processo da pesquisa-ação. Isso fez com que eu refletisse sobre a relação entre o padrão de admissão dos estudantes na pós-graduação e os recursos culturais das diferentes classes sociais, sobre o caminho das políticas de igualdade que atingem tanto o indivíduo quanto seu crescimento liberal, bem como as estratégias de incentivo à leitura na dimensão individual e organizacional.

\section{“Leitura" como critério de admissão dos estudantes na pós- graduação}

Yan é uma mestranda aprovada em setembro de 2009. Desde que iniciei minha carreira docente no Departamento de Gestão Educacional na Beijing Normal University, participo com bastante frequência das entrevistas da segunda fase do processo seletivo para o mestrado. Que tipo de pessoa é apta para fazer o mestrado? Na minha visão, é aquela que gosta de ler, pensar e escrever. Essa hipótese veio, primeiramente, da minha vivência pessoal: a primeira vez que ouvi alguém próximo de mim falar sobre se preparar para o processo seletivo de mestrado foi em 1987, quando eu tinha 15 anos. Era um professor de 28 anos de idade que dava aulas no ensino técnico. Ele lia bastante, tinha um pensamento crítico e sensível, e buscava uma personalidade livre. A imagem desse professor modelou o ideal inicial que eu imaginava dos candidatos do mestrado, tornando-os um padrão muito alto e baseado nas pesquisas acadêmicas. Eu mesma também aprecio a leitura. Entre os 
livros que me influenciaram antes de eu concorrer ao processo seletivo do mestrado encontram-se: Meu Encontro com Marx e Freud e a A Sociedade Sã, entre outros livros de Erich Fromm, filósofo e psicanalista norte-americano de descendência alemã, da escola de Frankfurt. 0 autor dedicava a fusão dos pensamentos de Sigmund Freud e Karl Marx, para explorar a interação da experiência do indivíduo com a estrutura social, e discutia os critérios para uma sociedade íntegra. Erich Fromm me fez redescobrir aquele Marx que analisava profundamente as condições do homem; aquele Marx que considerava o livre desenvolvimento do indivíduo como condição para o do coletivo. Li também O que é Educação do filósofo alemão Karl Jasper, A República de Platão, os quatro livros canônicos do confucionismo, Dao De Jing de Laozi, algumas obras do budismo, os poemas da dinastia Tang, Song e Yuan, as obras de Lu Xun e Hu Shi, entre outras leituras livres e complementares, as quais eram mais para saciar a curiosidade e transcendência espiritual. Portanto, a leitura e a escrita, inclusive as leituras e redações que realizava na minha terra natal Huhan junto com amigos, constituíram a minha prazerosa vida anterior ao mestrado. Pensava eu: "A vida acadêmica talvez seja assim".

Portanto, eu considerava gostar de ler como um dos pré-requisitos mais importantes para "os alunos que aprendem a pesquisa" ingressarem no mundo da pós-graduação. 0 que eu perguntava com mais frequência nas entrevistas era: "Qual é o livro que exerceu a maior influência na sua vida?", "Quem foi o autor?" e "Quais são as influências sobre você?" A resposta de Yan era uma coleção educacional Daxia, publicada pela editora da Huadong Normal University e Emílio de Rousseau. No entanto, a impressão não era forte. Após eu compreender profundamente a estrutura social da família de Yan, pude visualizar o contexto social de suas experiências de leitura e passei a refletir: a ideia de considerar a leitura como critério da aprovação para os estudos de pós-graduação é ou não é uma desconsideração da contextualização?

\section{Conhecendo o sujeito e a estrutura social da "leitura"}

Yan nasceu em 1985, num vilarejo da cidade L, província Shanxi, e seu irmão nasceu em 1991. Os pais de Yan nasceram em 1955 e ambos sofreram com a perda dos bisavós de Yan, ficando com a árdua responsabilidade de cuidar dos irmãos mais novos. 0 pai de Yan possui o ensino fundamental completo; já a mãe abandonou os estudos no quarto ano escolar. Eles se conheceram e casaram aos 28 anos de idade por meio de uma apresentação arranjada. 0 pai de Yan 
possui o hukou urbano ${ }^{5}$ e, inicialmente, residia na cidade, sem morar junto com a mãe, no campo. 0 hukou da mãe, por sua vez, é camponês; ela não tinha profissão, tampouco a própria propriedade. Quando Yan tinha cerca de três anos de idade, a companhia de construção civil na qual o pai trabalhava faliu; este por sua vez, foi demitido, retornou ao campo onde a mãe de Yan morava. Após o nascimento do irmãozinho, em 1991, o pai, então, saiu em busca de alguns empregos temporários. De vez em quando arranjava pequenas obras, melhorando gradativamente a condição econômica da família. A rememoração do apuro que a família vivenciou após a demissão do pai fez que as lágrimas precipitassem de Yan. Assim, estas experiências moldaram uma Yan forte e persistente. Desde a época do ensino fundamental, já pensava: “preciso me dedicar e esforçar bastante nos estudos. Quando eu crescer, quero ser alguém na vida, para que nós não sofrermos mais de bullying dos outros (...) desde pequena eu já desejava mudar o destino através dos estudos." ${ }^{6}$

Como a mãe, o hukou de Yan era do campo - cursou o ensino fundamental no vilarejo. A escola era composta por três, quatro casinhas; eram dois, três professoras; numa escola multisseriada. No seu terceiro ano, o vilarejo foi enquadrado na cidade; por isso construíram novos prédios na escola e aumentou o número de alunos e professores. Entretanto, a escola não possuía biblioteca, tampouco livros extracurriculares. Abraçando a fé de se dedicar aos estudos para se tornar notável na sociedade, Yan sempre obteve o mérito de ser a primeira colocada nas provas. Ela sentia que os professores e o diretor a tratavam melhor. No segundo semestre do seu quinto ano, ela foi selecionada como minirrepórter do Jornal Juventude da China, participou de um evento quando o Grupo Central foi para a sua cidade, além de ter publicado um artigo.

Depois de ter se formado no ensino médio, Yan foi aprovada pelo vestibular da Faculdade de Educação da Universidade H, em 2005, cujos 29 colegas eram de origem camponesa. No seu quarto ano da graduação, em 2009, Yan, junto com outros quatro colegas da sala, foram aprovados no programa de mestrado da Beijing Normal University. Na mesma turma ainda, cinco colegas obtiveram aprovação na Huadong Normal University, Huazhong Normal University, Northeast Normal University, Zhejiang Normal University, respectivamente, no programa de mestrado.

Na infância, Yan leu alguns livros de história em quadrinhos que adquiriu da casa do tio, como, por exemplo, Guerrilheiros ferroviários. Um dos professores do ensino

5. Hukou é uma espécie de registro que determina o local de moradia e trabalho da população. Foi criado com a intenção de controlar a migração do campo para a cidade.

6. Transcrição da entrevista de Yan realizada por Xiang Beili, 24 de setembro de 2011. 
fundamental the emprestava seus livros de história em quadrinhos e revistas. No ensino primário e secundário ela lia muito pouco livros extracurriculares, porque "os professores e meus pais diziam que eu precisava me dedicar aos estudos e que não devia ler esses livros. Quando minha mãe me via lendo, ela brigava comigo." ${ }^{7}$ No ensino primário, Yan tinha lido a revista Sociedade dos Contos, nunca leu romance. Já no ensino médio, usufruía biblioteca, mas apenas era permitida a leitura no local, não podia fazer empréstimo dos livros. Por outro lado, tamanha era a pressão dos estudos nesse período que Yan não tinha sequer tempo de ler os livros extracurriculares. Na cidade, havia uma livraria Xinhua. Nas lembranças de Yan, a livraria vendia livros de culinária, didáticos e instrumentais. Pela memória, ela recordava que provavelmente fora no ensino fundamental que a mãe a levara para aquela livraria, mas ela não tinha certeza. No ensino primário e secundário, Yan ia com os colegas à livraria, mas limitava-se à compra dos livros didáticos apenas.

Yan avaliou suas leituras na universidade como "muito superficial, muito pragmática". ${ }^{8}$ Quando estudava com os colegas, muitas vezes desistia da leitura pela metade. A coleção Daxia e Emílio eram os livros que ela lera na faculdade, mas que não deixaram impressões profundas. Yan responsabilizou o déficit da sua leitura pela falta da força de vontade própria e pelo fato de a pedagogia da universidade não exigir a leitura como obrigatoriedade.

Assim, não pude deixar de fazer uma retrospectiva do meu próprio interesse pela leitura: eu nasci no distrito Hanyang, cidade de Wuhan, em 1972. Meu pai, quando jovem, gostava de copiar poemas, era um soldado-poeta, que trabalhava no departamento de segurança e saúde numa empresa de cunho militar. Quando eu estudava no primário, ele me copiou um livro Aumentando a Sabedoria. Minha mãe era professora, assinou para mim e meus irmãos revistas como Literatura Infantil, Arte e Letras da Juventude, Jovens do Oriente, entre outros títulos, por mais de dez anos consecutivos. Minha tia sempre pedia emprestados livros da biblioteca da fábrica para podermos lê-los. Quando eu estudava no ensino fundamental, meus pais frequentemente me levavam à livraria Xinhua de Hanyag para comprar livros. À distância de uns 20 metros da minha casa havia uma sala de leitura. Antes de completar a idade suficiente para ingressar à escola, sempre guardava uns centavos para trocar por uma pequena placa de madeira, podendo ler histórias em quadrinhos uma atrás da outra dentro da sala. Naquela época, sempre havia estante de livros para aluguel e banquinhos na estrada ou no ponto de ônibus; assim, o tempo de espera do transporte era sempre o momento delicioso

7. Transcrição da entrevista de Yan realizada por Xiang Beili, 24 de setembro de 2011

8. Transcrição da entrevista de Yan realizada por Xiang Beili, em 24 de setembro de 2011. 
da leitura dos livros de história em quadrinhos. Durantes os anos de 1983 a 1986 nos tempos do ensino primário - todo mês eu recebia do meu pai cinco renminbi, quantia suficiente para solicitar um cartão de empréstimo das duas bibliotecas próximas da escola. Entre outros romances, eu lia obras de autores como Romain Rolland e John Christophe, traduzidas pelo senhor Fu Lei. Mas me interessavam principalmente os livros de artes marciais e as biografias, também traduzidas por Fu Lei. Após esse período, eu ingressei no ensino técnico. Além das leituras livres, dois professores, profundamente influenciados pelo espírito iluminista da década de 80 , sempre emprestavam livros a mim e a meus colegas, para discutirmos coletivamente. Os estudantes do ensino técnico de Wuhan fundaram diversas sociedades literárias e criaram seus próprios boletins. A participação nesses grupos junto com o intercâmbio com a "Juventude Literária" da sociedade literária Hudi de outra escola cultivou a longo prazo meu interesse por ler e escrever. Naqueles três anos, as impressões mais marcantes das leituras eram Seleção de Poemas do Impressionismo Moderno Chinês; Totto-chan: a menina ao lado da janela, de Testsuko Kuroyanagi; Quando o pôr-do-sol desaparecer, o livro que refletiu a Revolução Cultural, ciência e religião, de Li Ping; Eis uma terra mágica, o romance da juventude intelectual, de Liang Xiaosheng; Estrelas, de Daudet; entre outros romances não ficção que ruminam a Revolução Cultural.

Minha leitura e a de Yan são definidas pela contextualização históricocultural. Eu deduzo que as principais razões de nossas experiências no mundo da leitura serem diferentes são explicadas pela desigualdade dos recursos culturais das nossas famílias; da diferença cidade-campo quanto aos recursos culturais públicos; além da diferença na quantidade dos meios de veiculação dos conhecimentos entre as décadas de 1970 e 1990. Yan é uma mulher que nasceu em meados da década de 1980 e viveu na base da pirâmide social do campo, cujas condições econômicas eram frágeis e difíceis, consequentemente, impossíveis de fornecer recursos para a leitura. Por outro lado, o vilarejo onde Yan residia ficava incrustado no sistema paradoxal cidade-campo, cuja cultura deste último era deficitária, e o vilarejo não possuía biblioteca pública para amparar a escassez dos recursos culturais da família. Quando ela entrou na escola, a pressão das provas e a proibição da leitura extracurricular constituíram mais um muro entre ela e os livros. 0 seu interesse pela leitura não foi alimentado nem pela família, nem pelos recursos culturais públicos, tampouco pela escola. Já eu sou uma mulher que nasceu no início da década de 1970, numa família de classe média, no contexto de uma metrópole de Huazhong. As condições econômicas relativamente estáveis possibilitaram os recursos para a leitura, além do cultivo do interesse nela por meio da interação mútua com os professores e colegas que compartilhavam a mesma visão. Ao mesmo tempo, as bibliotecas e livrarias da cidade, entre outros 
recursos públicos abundantes, complementaram e suplementaram as possíveis insuficiências dos recursos culturais da família. Assim, meu encanto pela leitura, na verdade, nasceu num contexto social de uma família de classe média inserida no meio urbano.

Mediante a perspectiva histórica do contexto de meio de comunicação, ler é o principal recurso cultural nas décadas de 70 e 80 . A minha casa só adquiriu televisão em 1982; e o computador e a possibilidade de navegar na internet, somente em 1996. Nesse intervalo de 1970-1980 em que eu cresci, ler era provavelmente a área mais atraente para explorar o mundo dos conhecimentos. Já na visão de Yan, muitos dos seus colegas mestrandos de origem urbana também não leram suficientemente, talvez por causa do choque entre a televisão, computador, internet, entre outros meios de veiculação do conhecimento, e a leitura do livro.

0 resultado da pesquisa de Lareau (2010) também pode ser proveitoso para explicar as semelhanças e diferenças da leitura do indivíduo, família e recursos sociais nas classes sociais distintas: o ambiente da leitura interior de diferentes famílias da mesma classe social nem sempre é idêntico; por outro lado, nem toda família urbana proveniente da classe média possui recursos abundantes para a leitura. Ao mesmo tempo, também há possibilidade de a família camponesa de baixa classe social adquirir os recursos da leitura por iniciativa própria, ou pelo incentivo da sociedade, para a partir disso cultivar o interesse pela leitura dos membros da família. Por outro lado, cada indivíduo inserido na família da mesma classe social também pode manifestar reações distintas perante a leitura.

Portanto, é singular e especial cada experiência da leitura entrelaçada na contextualização do indivíduo, família e sociedade. Embora seja assim, no sistema paradoxal cidade-campo, é unânime a desigualdade dos recursos proporcionados para a leitura das famílias de classe social diferente: ao comparar os auxílios destinados à leitura da cidade e do campo, os recursos disponíveis à família camponesa da base da pirâmide social são consideravelmente deficitários em relação aos disponíveis à família de classe social inserida no meio urbano.

Reconhecendo que o interesse pela leitura e seus costumes são resultado da interação mútua do sujeito com a sociedade; e, ainda, considerando a discrepância das vivências de leitura nas estruturas sociais, comecei a refletir: será apropriado determinar a leitura como critério de aprovação no processo seletivo do mestrado? Candidatos de qual classe social possuem condições de desfrutar o cultivo dos recursos culturais para formar o costume da leitura? Levando como premissa a discrepância econômica e dos recursos culturais cidade-campo, os candidatos que, por limitações de recursos culturais, portanto, não formaram o costume pela leitura não deveriam ter oportunidade para entrar na pós-graduação? Conforme dados do Anuário Estatístico da Educação Chinesa, entre 1987 e 2009, a quantidade 
de pós-graduandos aumentou de 33.123 para 449.042. No entanto, muitos desses estudantes, depois de se formarem, não exercerão a pesquisa acadêmica. Ler, principalmente a leitura acadêmica, ainda deve ser considerado um critério decisivo para a aprovação?

Eu percebi que a consequência da falta de interesse pela leitura por parte dos estudantes de origem camponesa - decorrente de uma economia e distribuição cidade-campo injusta dos recursos culturais - não deveria ser arcada por eles. Atualmente, a leitura servirá somente como referência para a aprovação e para conhecer melhor o aluno, mas não como um critério decisivo para o ingresso. Somente quando o governo e a sociedade conseguirem proporcionar os recursos culturais suficientes para o campo, considerar a leitura como critério de aprovação dos candidatos ao programa de mestrado será devidamente justo.

Ao mesmo tempo, refleti sobre a relação entre o critério de aprovação para a pós-graduação e a assistência social como umas das missões da graduação. Em 2011, um processo do estudo de caso dos estudantes descendentes dos operários imigrantes, realizado por mim, junto com Yan e Jin, em uma escola de ensino fundamental em Beijing, despertou a vivência da participação do serviço social no campo educacional de Yan, na sua graduação. Yan, nos tempos da faculdade, foi vice-diretora da Sociedade Educação Nova Vida, da Universidade H. Esta mulher ativista já tinha liderado colegas para ensinar inglês a alunos, filhos dos camponeses, por um ano. A partir disso fiz uma retrospectiva em relação à pedagogia, estudos e função do serviço social da universidade, de cunho acadêmico. Se considerarmos que os candidatos à pós-graduação devam adquirir essas três aptidões, então, a experiência da assistência social poderia igualmente servir como critério de aprovação. Nesse sentido, a experiência de Yan é bastante rica. Ao reconhecer que as portas da pós-graduação devem ser abertas a Yan e seus colegas, o que ler e como ler tornaram-se problemas que eu redefini.

\section{Yan e eu, e a organização do grupo da leitura: mudando o processo da leitura conjunta}

Yan e eu lemos juntas no grupo da leitura e nas aulas. Ambas de nós mudamos. Pelas sugestões de Yan, eu modifiquei a organização do grupo da leitura. Em setembro de 2009, no início do ingresso de Yan, eu lhe atribuí a função de organizar o grupo da leitura. Os livros sugeridos se dividem em cinco áreas: os gerais da educação; a metodologia; as aulas e sua orientação; teoria da gestão educacional; e teoria da cidadania e educação.

Para a leitura inicial de Yan, eu recomendava as obras literárias educacionais. 
0 diálogo estabelecido entre diversos personagens proporcionou interpretações múltiplas do mesmo livro. No dia 20 de novembro e 2009, o nosso grupo coletivo de leitura discutiu o livro Totto-chan: a menina ao lado da janela, de Tetsuko Kuroyanagi. 0 coordenador pedagógico Wei, de uma escola de ensino fundamental de Chongqing, atentou às aulas da Escola Tomoe; já o diretor Lin, proveniente de uma escola de etnia minoritária de Guangxi, refletiu sobre o modelo escolar que ele construiria; o colega de Yan - Jin - definiu que a excelência de uma verdadeira escola é a liberdade espiritual; Yan explorou "a própria história do crescimento através da menina ao lado da janela, Totto-chan." Ela relembrava: alguns diretores e professores "não consideravam os alunos como pessoas" e the deixaram traumas enraizados na vida. Eu posicionei o ideal pedagógico da Escola Tomoe na perspectiva político-econômico-cultural da sociedade japonesa da primeira metade do século XX, na história da corrente Nova Escola e no contexto social para fazer a discussão. Antes do encerramento dessa reunião, Yan sugeriu a todos que lessem o livro Encontrando o desconhecido de si mesmo, de Zhang Defen. Para a mestranda, este é "um livro que ajudará significativamente o crescimento espiritual"10, para discutir como conhecer o verdadeiro eu ${ }^{11}$.

\section{A leitura dos livros acadêmicos e a mudança}

Ao entrar no segundo semestre do primeiro ano letivo, Yan começou a ler obras filosóficas e teóricas. A Yan que iniciou a jornada das leituras teóricas "de repente percebeu que, para ela, ler na verdade não era algo fácil"12. Em março de 2010, Yan lia com muito sofrimento Por que Arendt é importante?: "Lembro-me daquelas tardes dolorosas. 0 livro é muito difícil, não entendia (...) mas alguns pontos pequenos ainda consigo entendê-los"13. Numa reunião de estudos, no dia 12 de março de 2010, fiz a apresentação de Hannah Arendt (1906-1975), destacando sua biografia, seu pensamento e conceitos centrais como, "a banalidade do mal", “perdão, reconciliação e comunidade”. Também apresentei a metodologia de como escrever biografias, da autora Elisabeth Young-Bruehl ${ }^{14}$.

9. Ata do grupo de leitura de Totto-chan: a menina do lado da janela, 20 de novembro de 2009.

10. Transcrição da entrevista de Yan ralizada por Xiang Beili, 24 de setembro de 2011.

11. Ata do grupo de leitura de Encontrando com o desconhecido de si, 25 de dezembro de 2009.

12. Transcrição da entrevista de Yan ralizada por Xiang Beili, 24 de setembro de 2011.

13. Yan: Rascunho ensaísta. Disponível em: <http://www.renren.com/profile.do?id=232759694>. Acesso em: 29 mar. 2010.

14. Xiang Beili: relatório de leitura do Por que Arendt é importante?, 12 de março de 2010. 
No dia 7 de setembro de 2011, publiquei um artigo no Sina blog discutindo a "banalidade do mal, perdão e reconciliação" e a "verdade e reconciliação"15. Um mês depois, no dia 6, "Pequena criança boba", apelido de Yan no blog, comentou que, em 2010, o comportamento meritocrático de um dos funcionários do governo, ignorando as vítimas da enchente de Jiangxi, era a "banalidade do mal" 16 . A teoria de Arendt tornou-se uma perspectiva de Yan para "visualizar" e analisar os problemas, o que me fez muito feliz.

O segundo livro acadêmico que Yan leu foi uma leitura obrigatória nas aulas do mestrado sobre "pesquisas históricas da educação" - A metodologia dos estudos da História Chinesa -, do senhor Liang Qichao. Inicialmente Yan "ficou assustada”, mas gradativamente foi compreendendo "as afirmações interessantes do senhor Liang Qichao (...) por isso eu fui atraída pela sua fofura", e por fim "pela primeira vez fiquei profundamente interessada por livros acadêmicos"17. Yan comentou outras obras exigidas nas aulas no seu ensaio e relatório da leitura como: Autobiografia oral de Hu Shi, originado e escrito mediante entrevistas realizadas por Tang Degang; Diário de ir à escola, narrado por He Zhaowu e escrito por meio das entrevistas realizadas por Wen Jing; A História do Desenvolvimento da Educação Chinesa, de Yu Benfa e Xiong Xianjun; American Education: a History, de Wayne J. Urban e Jennings L. Wagoner, entre outros títulos. Na entrevista, Yan comentou sobre a experiência proporcionada das leituras: "Fiquei muito contente! Consegui tranquilizar a mente para poder ler muitos livros! Aquele período foi muito gostoso!"18

\section{As modificações ocorridas no grupo da leitura do coletivo acadêmico}

O livro Encontro com o desconhecido de si já faz parte da bibliografia do grupo. Este livro motivou a minha reflexão: o sujeito é um indivíduo completo que abrange corpo, espírito, consciência do conhecimento, até mesmo as emoções. Dessa forma, discutir o espírito do ser deve ser enquadrado no conteúdo das pesquisas educacionais. Na entrevista do dia 24 de setembro de 2011, contei para

15. Xiang Beili: Verdade e a Reconciliação. Disponível em: <http://blog.sina.com.cn/s/ blog_63008b0c0100ukyr.html>. Acesso em: 7 set. 2011.

16. Pequena criança boba: comentário disponível em: <http://blog.sina.com.cn/s/ blog_63008b0c0100ukyr.html>. Aceso em: 6 out. 2011.

17. Yan: Rascunho ensaísta, disponível em: <http://www.renren.com/profile.do?id=232759694>. Acesso em: 29 mar. 2010.

18. Transcrição da entrevista de Yan realizada por Xiang Beili, 24 de setembro de 2011. 
Yan a minha angústia em relação à organização do grupo de estudo, pedindolhe sugestões de como incentivar efetivamente a leitura e a discussão de todos. Ela propôs a leitura dividida em três fases: "no primeiro ano, a senhora pode continuar com as recomendações de livros prioritariamente literários com forte contexto educacional; no segundo ano, o tempo é relativamente maior, então pode ler livros mais teóricos; já no terceiro ano deve enfatizar na questão de como fazer a pesquisa"19. Assim, eu organizei o grupo da leitura da seguinte forma: Pós I e II comentários de livros e teses; Pós III - comentários de teses e desenvolvimento da dissertação de mestrado. Yan sugeriu que, como orientadora, eu deveria obrigar os mestrandos a lerem pelos menos uma obra a cada 15 dias, e fazer o relatório da leitura. Caso contrário, os alunos atrasariam a leitura, e por fim acabariam não tendo resultado algum. A partir disso eu fiz uma reflexão. Embora eu tenha organizado o grupo de leitura, por conta da negligência, após um determinado período, o resultado observado realmente foi infrutífero.

Yan gostaria que eu the desse mais orientações quanto à leitura. Por exemplo, em relação à teoria de "o papel do cidadão", ela desejava que eu "determinasse algumas bibliografias" e lhe orientasse as referências-chave para o entendimento ${ }^{20}$. Na entrevista, Yan citou dois eventos que nós duas experimentamos conjuntamente, para entender a obra What is Citizenship, de Derek Heater: por exemplo, a cidadania pode ser uma perspectiva teórica para discutir os direitos de acesso à educação dos estudantes, descendentes dos camponeses, de Beijing. Atualmente, entre as várias identidades dos descendentes camponeses - cidadão, camponês, descendentes de camponeses imigrantes, não cidadão da cidade -, o direito de acesso à educação ainda apresenta uma lacuna enorme. Num sistema de gestão educacional, conforme a organização de município como a base, como a prefeitura da megalópole de Beijing, que administra uma população de 19.610.000 habitantes[16], como garantir o direito de acesso à educação gratuita e obrigatória, assegurada pela legislação educacional, a todos os filhos de camponeses, cidadãos que vivem em Beijijng, e cidadãos de outras classes sociais? Além disso, no dia 6 de novembro de 2009, publiquei um comentário a respeito de um texto divulgado pelo departamento de controle de doenças da agência sanitária de Beijing. 0 município de Beijing estenderá a vacinação contra a gripe H1N1 a todo cidadão - também discuti a questão de a vacinação não atender os cidadãos que trabalham na cidade e que não possuem identidade registrada em Beijing ${ }^{21}$. No segundo dia em que

19. Transcrição da entrevista de Yan realizada por Xiang Beili, 24 de setembro de 2011

20. Transcrição da entrevista de Yan realizada por Xiang Beili, em 24 de setembro de 2011.

21. Xiang Beili: A identidade dos cidadãos na vacinação contra gripe H1N1. Disponível em: <http:// eblog.cersp.com/userlog/4090/archives/2009/1283089.shtml>. Acesso em: 6 nov. 2009. 
postei o texto, "Pequena criança boba", apelido cibernético de Yan, comentou sobre a política de hukou: “(...) já é tempo de mudar"22. Após a entrevista, em 17 de outubro de 2011, Yan novamente comentou - desta vez, a perspectiva de cidadão, residentes da cidade, e camponês ficou bastante esclarecida: “(...) caso não desfaçam as limitações entre as cidades e províncias, a desigualdade dos direitos dos cidadãos e residentes da cidade não será eliminada. Quando refletida na educação, o problema de acesso à educação dos filhos, descendentes dos camponeses imigrantes, é um ótimo exemplo"23.

\section{Igualdade nos recursos culturais: o comprometimento da educação dos pós-graduandos}

Yan, que não usufruiu os recursos de leitura na família, campo, escola e graduação, começou a desfrutar o prazer de ler nos estudos da pósgraduação. Felizmente, superando todas as dificuldades, Yan desafiou de forma insistente o ambiente desfavorável, proporcionado pela estrutura social, e entrou pela porta da pós-graduação com muita coragem. Assim, nós pudemos, em conjunto, por meio da interação com parceiros, realizar a retrospectiva da experiência de leituras, esforçando-nos e auxiliando uns aos outros. Minha vivência de leitura e a de Yan, assim como o coletivo acadêmico formado pelos estudantes e diretores, obtiveram transformações neste processo.

\section{Conclusão e debate: desenvolver a pesquisa-ação com base na contextualização do sujeito e dos problemas educacionais}

\section{Identificar a contextualização do sujeito e dos problemas educacionais mediante a perspectiva da sociologia histórica}

A perspectiva de considerar o "sujeito" como uma interação mútua do indivíduo inserido em um determinado tempo histórico com a sua estrutura

22. Pequena criança boba: $n .^{\circ} 2$ discussão: $A$ identidade dos cidadãos na vacinação contra gripe H1N1, Disponível em: <http://eblog.cersp.com/userlog/4090/archives/2009/1283089.shtml>. Acesso em: 7 nov. 2009.

23. Pequena criança boba: $n .^{\circ} 17$ discussão: $A$ identidade dos cidadãos na vacinação contra gripe H1N1. Disponível em: <http://eblog.cersp.com/userlog/4090/archives/2009/1283089.shtml>. Acesso em: 17 out. 2011. 
social pode ser denominada de perspectiva da sociologia histórica. Tendo por referência a proposta de que é preciso adotar a perspectiva histórica para realizar as análises de estrutura e transformação social (Xia, 2004), eu penso que as perspectivas históricas apresentadas a seguir beneficiarão 0 "visualizar" da criança e do aluno no contexto da história e da sociedade:

I) Compreender que a criança, o aluno, inclusive o próprio pesquisador é uma existência da interação mútua entre a ação individual do tempo histórico determinado e a sua estrutura social. 0 sujeito existe na função interativa de si com sua história político-econômica, cultural e social institucionalizada vertical e horizontalmente. Há semelhanças quanto às condições e recursos culturais do mesmo período e da mesma família; no entanto, em relação à experiência pessoal, nesta interação com variados fatores, já demonstra diferenças;

II) Discutir como a literatura infantil e os problemas educacionais mostram os modelos específicos da estrutura social e a singularidade e diversidade dos modos de transformação. A ficção autobiográfica de Vasconcelos, a pesquisa de Laureau, a pesquisa da professora Chen Huimin, a minha pesquisa-ação com Yan demonstraram respectivamente a família brasileira de baixa classe social do Brasil da década de 1920; a família dos operários norte-americanos da década de 1990; a singularidade e diversidade, semelhanças e diferenças da estrutura social e modo de transformação das famílias de classe camponesa e classe média taiwanesas e chinesas da década de 2000.

\section{Retrospectiva: meu processo de pesquisa-ação e de Yan sobre a leitura}

Baseei-me no exemplo da pesquisa-ação sobre a leitura, realizei uma retrospectiva do processo da pesquisa; organizei a metodologia da pesquisa; defini os conceitos como "visualizar", "contextualização" e "pesquisa-ação"; examinei a validade interna da pesquisa; e discuti as características da "pequisa-ação". 
Figura 1 - 0 processo da pesquisa-ação da leitura

Problema 1 - A leitura deve ser considerada como critério de aprovação da pós-graduação no programa de mestrado?

Refletir sobre este critério na própria experiência:

- A imagem do professor como o ideal dos pós-graduandos,

- A minha interpretação dos pós-graduandos.

Identificar e visualizar meu contexto individual e sócio-histórico da leitura e o de Yan

Discutir as razões das diferenças na experiência de leitura

- Visualização 1 - A desigualdade dos recursos culturais das classes sociais em que a família está inserida, a diferença dos recursos públicos cidade-campo.

- Visualização 2 - A modificação dos meios de veiculação do conhecimento das décadas de 1970-1990.

- Visualização 3 - A existência da semelhança e diferença do sujeito, família e recursos sociais

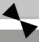

\section{Redefinição do problema}

Problema 1: Leitura não poderá ser critério de aprovação, como ler conjuntamente com Yan?

Problema 2: Discutir se os livros espirituais deveriam ser lidos.

Problema 3: Como coordenar melhor o grupo da leitura.

Problema 5: Como orientar eficientemente a leitura dos estudantes

Explorar e realizar as estratégias ativas de leitura através da interação intersubjetiva entre mim e Yan

A experiência da leitura obteve transformação através da interação intersubjetiva e relações entre colegas (Yan, eu e nosso grupo de leitura almejaram a mudança)

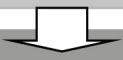

A pedagogia da pós-graduação herdou a distribuição injusta dos recursos de leitura que Yan vivenciou anteriormente 


\section{Metodologia de pesquisa}

Entrevistas: em 24 de setembro de 2011 e 13 de outubro de 2013, realizei respectivamente a primeira entrevista com Yan e uma complementar, organizando a contextualização social em que a família dela se insere, sua experiência da leitura, suas sugestões em relação ao grupo de leitura.

Análise dos dados: analisei 13 dados.

- Duas atas do grupo de leitura (Totto-chan: a menina do lado da janela, 20 de novembro de 2009; e Encontrando com o desconhecido de si, 25 de dezembro de 2009);

- Um relatório de leitura (Xiang Beili: Relatório de leitura do Por que Arendt é importante?, 12 de março de 2010);

- Um ensaio da leitura de Yan (Yan: Um rascunho ensaísta, 29 de março de 2010)

- Dois artigos meus no Sina Blog (A identidade dos cidadão na vacinação contra gripe H1N1, 6 de novembro de 2009; A verdade e a reconciliação, 7 de setembro de 2011);

- Três comentários de Yan (7 de novembro de 2009; 6 de outubro de 2011; e 17 de outubro de 2011);

- Três e-mails da discussão de Yan comigo (17 de outubro de 2011; 18 de outubro de 2011);

- Uma anotação de feedback de uma tese (17 de outubro de 2011).

Esses dados demonstraram como Yan e eu interagimos intersubjetivamente durante o processo da pesquisa; como eu redefini o problema inicial; como a experiência de leitura obteve transformações nessa interação intersubjetiva e nas relações com outros colegas; como examinar a validade interna do artigo; como a pedagogia da pós-graduação herdou a distribuição injusta dos recursos para a leitura que Yan outrora vivenciara.

\section{Definições normativas da diferenciação dos conceitos}

O que é "visualizar"? "Visualizar" é uma identificação autoperceptiva do próprio pesquisador, resultado do processo interativo da sua subjetividade e experiências vividas no passado com o mundo. Ao contrário do paradigma da pesquisa empírica que tenta eliminar a subjetividade, a pesquisa-ação a considera o principal objetivo da pesquisa. 0 "visualizar" do pesquisador é exatamente por meio da sua subjetividade e experiências vividas no passado para escolher os objetos observados e interpretar tudo o que visualizou (King, 1989). A experiência antiga 
proveniente da vida e da pesquisa acadêmica limita a possibilidade e o conteúdo da identificação: o pesquisador, nas suas diferentes etapas de experiência da vida e de conhecimento acadêmico, terá provavelmente capacidade e perspectiva de interpretação diferentes na identificação do mesmo objeto, e pesquisadores diferentes apresentam aspectos distintos quanto à capacidade e interpretação na identificação. Exatamente por isso o "espelhamento" como “água limpa de um lago" é diferente do de "reflexo do mundo subjetivo dentro da cabeça do homem" (Xia, 2007). 0 que o espelho consegue refletir, identificar, visualizar certamente é o reflexo encarregado da experiência objetiva do pesquisador interagindo com o mundo exterior. É certo que refletir carrega a característica funcional de interação, como afirma Dewey sobre a interação da "experiência": "É como um todo, ela não admite qualquer separação material da ação; objetividade e subjetividade, mas sim é abrangente como um todo indivisível" (Dewey, 1981). A minha interpretação do contexto da leitura é exatamente a minha interpretação atual.

O que é a "contextualização"? O Dicionário do Mandarim Moderno explica: “A medicina tradicional chinesa considera como os vasos sanguíneos e a rede dos meridianos" (2005, p. 214). No corpo físico, o complexo sanguíneo e meridiano sustenta a existência do corpo e as sensações; a contextualização exterior do corpo é a relação horizontal e vertical das experiências pessoais com a sua estrutura social-político-econômico-histórico-cultural, é uma interação, o estado do sujeito. 0 complexo sanguíneo e meridiano da interação e entrelaçamento do sujeito com a sociedade promovem a alimentação e limitação do crescimento. Nas várias conversas com Yan, eu fui visualizando a contextualização unilateral cidade-campo da leitura para reconhecimento do entrelaçar dos contextos multifacetados.

0 que é a pesquisa-ação em educação? Para mim, é a vida aliada oriunda da relação de parceria entre o pesquisador e o participante. É compreender e interpretar o sujeito e os problemas educacionais na contextualização interativa do sujeito com o social, para construir uma sociedade sã e mais justa. É a pesquisa que proporciona ao pesquisador e participante os problemas e os espaços de avanços e melhorias.

\section{Exame da validade interna}

O participante é o parceiro do pesquisador-ator para atuar juntos na identificação do problema, buscar estratégias experimentais e, ao mesmo tempo, participar do exame da validade interna da pesquisa-ação: a descoberta da pesquisa é racional? Em relação ao objeto de pesquisa e ao leitor, a pesquisa realmente adquiriu credibilidade? Em relação àquilo 
que observamos, nós fizemos uma descrição autêntica? (Miles; Huberman, 2006). Por não interpretar a consciência psicológica social do participante, baseei-me na validação comunicativa para examinar a validade interna (Flick, 2007). Na noite de 16 de outubro de 2011, enviei o artigo a Yan para certificar se descrições sobre esta estavam condizentes, e the pedi feedback da apresentação e do conteúdo da pesquisa. Na madrugada do dia 17, Yan comentou via e-mail e via artigo. Ela anotou no artigo que muitos dos mestrandos provenientes da cidade também leem pouco - por isso a leitura nos anos de 1970-190 ainda sofre a influência da quantidade dos meios de veiculação do conhecimento (Xia, 2004). Sendo assim, eu alterei meu texto, adicionando a quantidade dos meios de comunicação como uma das razões; ao mesmo tempo eu "aprecio e respeito" a confiança de Yan por $\mathrm{mim}^{24}$. Exclui alguns conteúdos pessoais da entrevista que não se relacionavam com o presente artigo. Na madrugada de 18 de outubro, eu the reenviei o artigo corrigido e the consultei sobre chamá-la de "Yan". Trinta minutos depois, ela respondeu que não havia inconveniência alguma em a chamar de "Yan" e também disse: "não tenho mais sugestões!"25

\section{As características e valores da discussão da pesquisa-ação na educação}

Na pesquisa-ação em educação, identificar e reconhecer o contexto são as condições para a redefinição dos problemas iniciais; são perspectivas teóricas de discutir as razões da origem dos problemas; além de serem a oportunidade de transformação e aperfeiçoamento. A professora Chen Huimin, por ter visualizado justamente a contextualização do déficit das condições culturais nas famílias dos alunos, redefiniu, então, os problemas da pesquisa: Quais são as tarefas adequadas? Quais são os recursos que a escola pode oferecer para auxiliar os alunos, cujas condições culturais na família são insuficientes, a assimilarem as competências de pesquisar?

Já na pesquisa-ação sobre a leitura, foi exatamente em função da visualização do meu contexto pessoal e histórico-social de leitura e o de Yan que eu redefini o problema "Leitura deve ser critério de aprovação para pósgraduação do programa de mestrado?" para "Não sendo a leitura critério de aprovação, como ler juntamente com Yan?"

24. E-mail resposta de Xiang Beili a Yan, 18 de outubro de 2011.

25. Feedback de Yan no artigo, 18 de outubro de 2011. 
No processo da discussão e execução de estratégias ativas de leitura, a interação intersubjetiva entre mim e Yan fez nascer incessantemente outras redefinições do problema inicial. Portanto, “Eleger o problema - Identificar e discutir as razões do problema - Redefinir o problema - Executar as estratégias ativas - Melhorar", são ações que se influenciam mutuamente, avançando espiritualmente para a progressão da pesquisa.

Figura 2. 0 processo da pesquisa-ação em educação

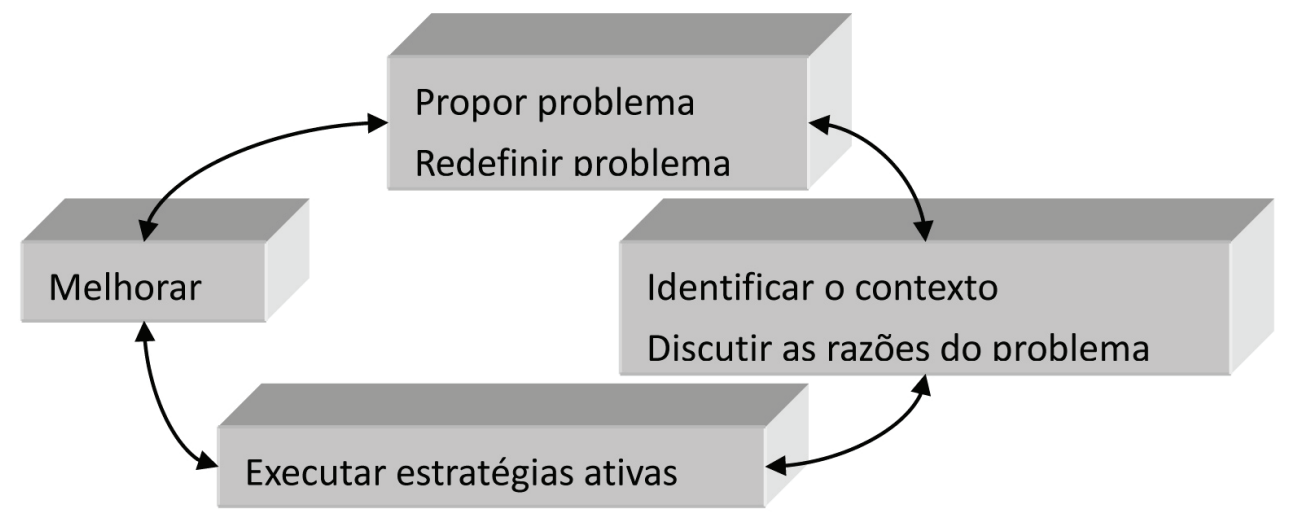

A pesquisa-ação é sobre os “atores", isto é, o pesquisador e o participante estabelecem a relação de confiança da parceria. É na interação desses atores que a vida deles se transforma e melhora (Xia, 2004). Donald A. Schön pensa que o pesquisador-ator-realizador-da-reflexão precisa ter coragem para enfrentar diretamente a complexidade, a incerteza, a instabilidade, a singularidade e o choque de valores diferentes proporcionados na prática situacional. Como Dewey afirma em Lógica: a teoria da investigação, o problema se constitui nas situações desequilibradas e incertas; é necessário, muitas vezes, o experimento da angústia, preocupação ou dúvida, para que possamos entendê-lo profundamente. 0 pesquisador-ator não se autodetermina como o único capaz de promover orientações relacionadas e importantes, nas específicas situações. 0 pesquisador considera sua própria incerteza o material de aprendizagem de si mesmo junto com o participante. (Schön, 2007, p. 14)

Na minha pesquisa-ação junto a Yan, julguei a nossa relação como “sujeito - sujeito", somos parceiros da cooperação na investigação. Nós 
conversamos, lemos e compreendemos juntas; eu também the abri minha angústia e incerteza sobre como coordenar o grupo de leitura, considerandoas como material de estudo na nossa aprendizagem. Por isso, Yan me sugeria modificações da organização do grupo de leitura. A pesquisa-ação se dedica à promoção de uma sociedade mais justa. A herança educacional dos pósgraduandos está criando as condições de leitura para Yan, incentivandolhe desfrutar mais igualitariamente os recursos culturais. Na dimensão do tratamento de objetividade, da relação do pesquisador com o participante, do objetivo e valor da pesquisa, a pesquisa-ação em educação consiste em reestruturação da filosofia da pesquisa educacional.

\section{A pesquisa-ação em Educação: do conhecer ao reconhecer}

Do "conhecer" ao "reconhecer" é um caminho extenso. Como e quando minha percepção consciente e compreensão da existência interativa do sujeito com seu contexto histórico-social, seguida da interpretação de cada sujeito como "o ator da contextualização", contribuirão para melhorias na vida educacional? O processo entre o "conhecer" e o "reconhecer" não exige apenas tempo, mas condições de experimentar e despertar. Deixo um pequeno poema, escrito por mim em 2009, como descrição da (des) construção da leitura.

\section{(Des)construção}

Do nascer aos 33 anos é a história da construção;

Dos 34 anos até hoje é a história da desconstrução. Construir requer provavelmente anos de dedicação incessante. Desconstruir necessita provavelmente apenas de um instante.

Desconstruir:

Não é um súbito desabamento, não obstante rachando, esmoronando, caindo, silenciosamente, pedaços irregulares e espalhados são o todo restante.

Cada pedaço é cheio de cores, formas, aparências da própria vida, misturando os próprios sofrimentos, dor, alegria e felicidade; Cada pedaço resiste ser rotulado pelas narrativas uniformes e gigantes.

0 espalhamento dos fragmentos intensos e vivos, fazendo com que "complexidade" e "diversidade" sendo visualizadas Referências 
$X I A$, Linqing. A formação local do homem: o profissional da psicologia da educação nos desdobramentos político-histórcos. Pesquisa da Psicologia Aplicada, v. 31, pp. 201-239, 2006.

. Uma lâmpada suficiente: identificar o caminho descoberto [J]. Pesquisa de Pscologia Aplicada, v. 23, pp. 131-156, 2004.

. Prefácio do tradutor. A linha da pipa não rompe: a prática enraizada e profunda do realizador. $\mathrm{SCHON}$, Donald. 0 realizador da reflexão: como um profissional reflete nas ações. Tradução: Xia Linqing. Beijing: Editora Ciências da Educação, 2007.

VASCONCELOS, José Mauro de. Meu querido pé de laranja lima. Tradução: Wei Ling. Beijing: Editora Tiantian, 2010.

.Wikipedia. Disponível em:<http://en.wikipedia.org/wiki/Jos\%C3\%A9_ Mauro_de_Vasconcelos>. Acesso em: 15 ago. 2010.

MATIN, Cheryl E., Wasserman Mark. História da América Latina. Tradução: Huang Lin. Haikou: Editora Hainan, Editora Sanhuan, 2007.

Bethell Leslie (Org.). História da América Latina da Cambrigde. v. V. Tradução: Huyuding e outros. Beijing: Editora da Literatura de Ciências Sociais, 1992.

BURNS, E. Bradford. História condensada da América Latina. Tradução: Wang Ningkun. Changsha: Editora da Educação Hunan, 1989.

XIANG, Beili. A ternura necessita da segurança econômica básica [J]. Boletim Semanal Xinmin, v. 39, n. 610, pp. 52-55. 11 out. 2010-17 out. 2010.

ZHOU, Xiaopo. A ternura amortecer o coração da criança travessa do que castigo [J]. Revista Educação Chinesa, v. 10, 07 set. 2010.

LAREAU, Annette. A infância desigual. Tradução: Zhang Xuze. Editora da Universidade de Beijing, 2010.

MA, Li. 0 ponto de partida teórico da criação da Literatura Infantil: a essência da criança é ao sujeito. Jornal da Universidade Normal de Shenyang, Sessão de Ciências Sociais, v. 3, p.99. 2005.

WU, Shiying. Deixar que o passado revele o futuro - auto-descrição dos 80 anos de Wu Shiying [J]. Jornal de Estudos Educacionais, v.5, pp.3-12. 2009. WANG, Quangen. Literatura infantil e ensino de língua no ensino fundamental. Guangzhou: Editorial educacional de Guangzhou, 2006.

AGÊNCIA DO PLANEJAMENTO FINANCEIRO DO CONSELHO NACIONAL DA EDUCAÇÃO. Anuário estatístico da educação chinesa (1987). Editora da Universidade Industrial de Beijing : Beijing, 1988.

MINISTÉRIO DA EDUCAÇÃO DA REPÚBLICA POPULA DA CHINA. Anuário estatístico da educação chinesa. Editora da Educação do Povo : Beijing, 2010. AGÊNCIA NACIONAL DE ESTATÍSTICA. Boletim oficial do VI censo nacional 
de demografia, 2010. n. 2. Disponível em: <http://www.stats.gov.cn/tjfx/jdfx/ t20110429_402722512.htm>. Acesso: 29 abr. 2011.

SKOCPOL, Theda. A imaginação histórica da sociologia. A perspectiva e metodologia da Sociologia histórica. Tradução: Feng Jiwen e outros. Shanghai: Editora Popular de Shanghai, 2007.

KING, Edmund. A escola do outro país e nossa escola: a educação comparativa de hoje. Tradução: Wang, Chengxu e outros. Beijign: Editora da Educação do Povo, 1989.

DEWEY, John. Experiência e Natureza. Obras selecionadas de teoria educacional de Dewey. Tradução e organização de: Zhao Xianglin e Wang Chengxu. Shanghai: Editora da Universidade Normal de Huadong, 1981.

EDITORA DE DICIONÁRIO DO INSTITUTO DE LÍNGUAS DA ACADEMIA DE CIÊNCIAS SOCIAIS DA CHINA. Dicionário do mandarim moderno. 5. ed. Beijing: Imprensa comercial, 2005. p.914.

MILES, M. B.; HUBERMAN, A. M. Análise de dados da pesquisa qualitativa. Tradução: Zhang Fenfen. 2. ed. Taipei: Shuangye Galeria de Livros Ltd., 2006. FLICK, Uw. Introdução à pesquisa qualitativa. Tradução: Li Zhengxian, Liao Zhiheng, Lin Jingru. Taipei: Wunan editora Ltd, 2007.

SCHÖN, Donald. A. O Realizador da reflexão: como um profissional reflete nas ações. Tradução: Xia Linqing. Beijing: Editora Ciências da Educação, 2007. XIANG, Beili. (Des)construção. Anais do Congresso Estreito China-Taiwan sobre a Pesquisa-ação, 2010.

Recebido em maio de 2015

Aprovado em maio 2015

XIANG Beili, da etnia han, natural de Hubei, é professora associada do Departamento de Gestão Educacional da Beijing Normal University. Doutora em História da Educação pela Beijing Normal University (China) e estudos de pós-doutorado pela Stanford University (EUA). E-mail: blxianglabnu.edu.cn 